\title{
Analysis of Transient Boiling Processes during Steel Quenching in Water PAG Solutions to Decrease Distortion
}

\author{
Nikolai I. Kobasko and Anatoly A. Moskalenko
}

\begin{abstract}
The paper discusses results of testing standard cylindrical probe $12.5 \mathrm{~mm}$ diameter in water polymer solutions which was additionally instrumented with a surface thermocouple. It is shown that central thermocouple cannot depict many physical phenomena taking place during quenching in polymer solutions such as shoulder formation, self- regulated thermal process establishing, surface temperature transient from film boiling to nucleate boiling process. Moreover, it is shown that experimental data depicted by central thermocouple cannot be used for solving inverse problem to analyze quenching process in liquid media. Along with analyzing film and nucleate boiling processes during quenching, the paper discusses the possibility of quality quench process control via using sonar system. It is established an equation for evaluating duration of transient nucleate boiling process. As an example, the cooling characteristics of fresh and old polyalkylene glycol (PAG) polymer solutions are analyzed. It is shown that with passing time the critical heat flux density of polymer decreases and inverse solubility effect disappears. That is while the method and apparatus were developed to control in industrial condition the quality of quenched steel parts during hardening in liquid media.
\end{abstract}

Keywords - analysis, correctness, duration, film and nucleate boiling, quality control, surface thermocouple.

\section{INTRODUCTION}

Currently, there are several ASTM Standards for testing the cooling intensity of liquid quenchants [1], [2]. They all are based on cooling temperature - time curves and core cooling rate curves analysis [1]-[3]. The diameter of a standard cylindrical probe is $12.5 \mathrm{~mm}$ and its length is $60 \mathrm{~mm}$ which is made from Inconel 600 material and is instrumented with one thermocouple at its center [1], [3]. The designed standards allow maintaining liquid quenchants in stable conditions and provide their perfect control by comparing cooling curves with each other. Such an approach works perfectly for industrial oils and elevated concentration polymers in water where, as a rule, cooling process lasts almost to bath temperature. Nowadays, in the heat treating industry intensive quenching (IQ) process is used that requires cooling time interruption at proper time depending on chemistry of steel and condition of cooling. To design computer program for cooling time interruption suitable for any steel, and any form and size of hardened product, heat transfer coefficients (HTCs) are required for each specific condition of steel hardening. The task is rather complicated connected with the solving of inverse problem (IP) which belongs to ill-posed problem [4]. When the thermocouple is located at the center of the probe, incorrect results of calculations of HTCs occur. Moreover, nobody knows how to obtain such a way HTC that can be transferred to more complicated steel parts made of different materials. There were many unsuccessful attempts to perform transition from standard probe to real steel part. The problem is not solved yet and each specific technology every time requires additional costly experiments.

Current paper discusses the process of cooling in low concentrations of fresh and old water PAG polymer solutions [5], [6] exploring standard probe instrumented with two thermocouples located on the surface and its center to investigate accurately transient nucleate boiling processes taking place during quenching.

\section{FILM AND Nucleate BoIling PRocesses DuRING Quenching}

It was firmly established that film boiling during quenching in cold water salt solutions of optimal concentration is completely absent [7], [8]. Only transient nucleate boiling process and convection take

Submitted on Novembber 06, 2021.

Published on Novembber 27, 2021.

N. I. Kobasko, Intensive Technologies Ltd, Kyiv, Ukraine.

(e-mail: nkobasko@gmail.com)

A. A. Moskalenko, Institute of Engineering Thermophisics of NASU, Kyiv, Ukraine.

(e-mail: an.moskalenko@gmail.com) 
place in this case which is strongly governed by Eq. (1) [9], [10]:

$$
\tau_{n b}=\bar{\Omega} k_{F} \frac{D^{2}}{a}
$$

where $\tau_{n b}$ is the duration of transient nucleate boiling process; $\bar{\Omega}$ is a value which depends on initial temperature and characteristics of the cooling system; $k_{F}$ is form coefficient; $D$ is the thickness of quenched sample; $a$ is thermal diffusivity of material. The aim of the current paper is an investigation to see whether obtaining equation (1) is true for water polymer solutions of inverse solubility when concentration is very low. For this purpose, were performed experiments in lab conditions exploring the measuring system shown in Fig. 1 [11].

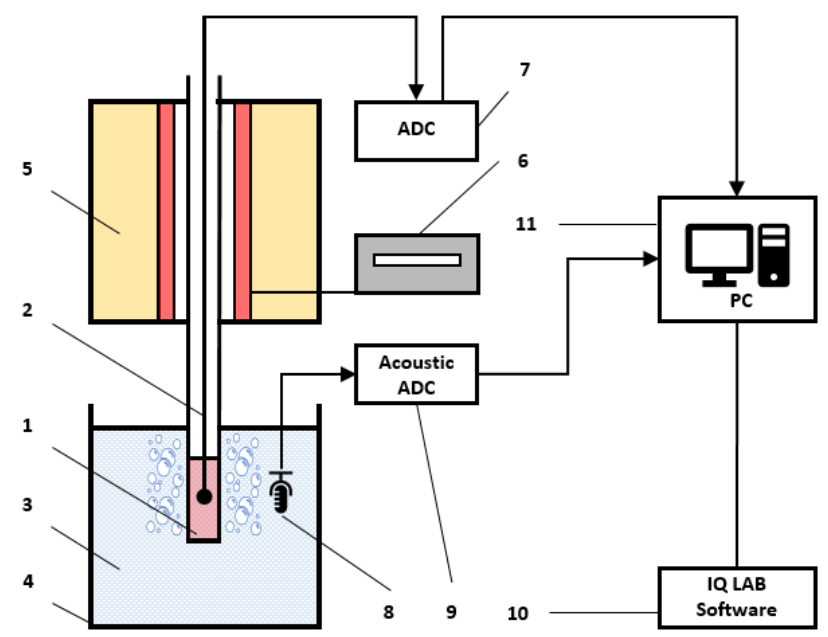

Fig. 1. Diagram of the hardware-software complex for thermoacoustic diagnostics of transient boiling processes during quenching probes in evaporable liquids [11]: 1 - temperature probe; 2 - temperature sensor in the center of the probe; 3- water solution of $\mathrm{NaCl}$; 4-coolant container; 5- heating furnace; 6- thermostat; 7- analog digital converter of temperature sensor; 8- hydrophone; 9- acoustic analog digital converter; 10- experimental data registration and processing program IQLab.

In contrast to the widely used standard cylindrical probe $12.5 \mathrm{~mm}$ in diameter with one thermocouple at its center, authors used standard probe with two thermocouples: at its center and on its surface. After surface thermocouple welding, the surface of probe was accurately polished. Experiments were performed in cold distilled water at $17^{\circ} \mathrm{C}$ and low concentration $1 \%$ of water polymer solution.

Disadvantages of cooling curve measurement by one central thermocouple of standard probe are:

- Impossibility to evaluate and analyze self-regulated thermal process during quenching in liquid media.

- Impossibility to investigate effect of shoulder formation on the surface of cooling curve caused by surface polymeric layer variation.

- Impossibility to differ four types of heat transfer modes taking place during quenching probe in vaporizable liquids.

To support the above discussed, Fig. 2 shows cooling curves versus time obtained during quenching standard probe with two thermocouples in distilled water at $17^{\circ} \mathrm{C}$.

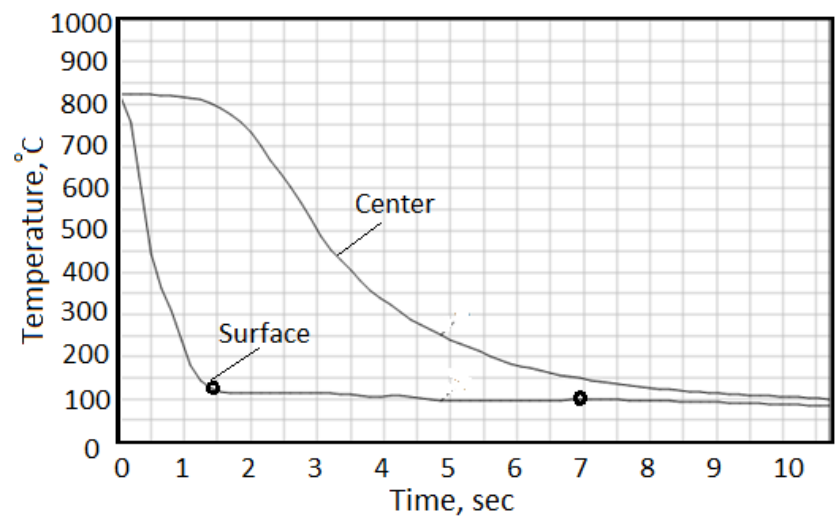

Fig. 2. Surface and core cooling curves versus time during quenching of standard probe is still distilled water at $17{ }^{\circ} \mathrm{C}$. 
As seen from Fig. 2, the surface temperature of the standard probe drops from $825{ }^{\circ} \mathrm{C}$ to $125{ }^{\circ} \mathrm{C}$ for 1.3 $\mathrm{s}$ and then maintains at the level of $100^{\circ} \mathrm{C}$ for relatively a long time (see Fig. 2 and Table I). The film boiling process in this case is absent that coincides very well with experiments of French (see Table II) [8]. As known, French [8] published very accurate experimental data showing absence of film boiling process during quenching small and large probes in $5 \%$ water solution of $\mathrm{NaOH}$ moving at $0.914 \mathrm{~m} / \mathrm{s}$ (see Table II). Later similar experiments were performed by author [12]-[14] who carefully investigated self-regulated thermal processes and established regularities of transient nucleate boiling process governed by Eq. (1). Since during self-regulated thermal process surface temperature maintains a long time at the level of boiling point of a liquid and very slightly decreases, it was assumed that surface temperature during self-regulated can be considered approximately as a constant value. Such approximation doesn't generate visible errors. Based on this fact, new technologies, called IQ-2 process, were developed [7].

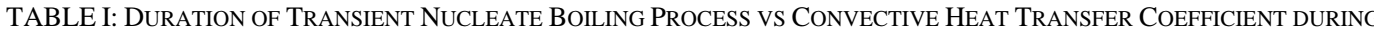

\begin{tabular}{ccccc}
\multicolumn{4}{c}{ QUENCHING STANDARD PROBE } & \multicolumn{4}{c}{$(12.5$ MM DIAMETER) IN LIQUID MEDIA } \\
\hline HTC $_{\text {conv }}$ & $\vartheta_{I}$ & $\vartheta_{I I}$ & $\bar{\Omega}$ & $\tau_{n b}, \mathrm{~s}$ \\
\hline 300 & 31 & 6.15 & 5.67 & 7.09 \\
400 & 31 & 6.7 & 5.44 & 6.80 \\
500 & 31 & 7.17 & 5.18 & 6.48 \\
600 & 31 & 7.58 & 5.0 & 6.25 \\
700 & 31 & 7.93 & 4.86 & 6.08 \\
800 & 31 & 8.25 & 4.73 & 5.91 \\
900 & 31 & 8.55 & 4.61 & 5.76 \\
1000 & 31 & 8.8 & 4.52 & 5.65 \\
1200 & 31 & 9.3 & 4.35 & 5.44 \\
\hline
\end{tabular}

TABLE II: TIME REQUIRED FOR THE SURFACE OF STEEL SPHERES OF DIFFERENT SizeS TO COOL TO DIFFERENT TEMPERATURES WHEN QUENCHED FROM $875^{\circ} \mathrm{C}$ IN 5\% NAOH-WATER SOLUTION AT $20^{\circ} \mathrm{C}$ AND MOVING AT 0.914 M/s, ACCORDING TO FRENCH [8]

\begin{tabular}{ccccccccc}
\hline \multirow{2}{*}{ Size, $\mathrm{mm}$} & 700 & 600 & 500 & 400 & 300 & 250 & 200 & $150^{\circ} \mathrm{C}$ \\
\cline { 2 - 9 } & 0.027 & 0.037 & 0.043 & 0.05 & 0.09 & 0.15 & 0.29 & 0.69 \\
12.7 & 0.028 & 0.042 & 0.058 & 0.071 & 0.11 & 0.15 & 0.26 & 0.60 \\
25.4 & 0.033 & 0.042 & 0.055 & 0.074 & 0.13 & 0.21 & 0.35 & 0.82 \\
63.5 & 0.023 & 0.039 & 0.065 & 0.093 & 0.14 & 0.19 & 0.32 & 0.59 \\
\hline
\end{tabular}

According to French, cooling time from $875^{\circ} \mathrm{C}$ to $150{ }^{\circ} \mathrm{C}$ in electrolytes doesn't depend on size of probe (see Table II). It means that small and large probes at the very beginning of cooling within interval of temperatures $750{ }^{\circ} \mathrm{C}-150{ }^{\circ} \mathrm{C}$ can be considered as a semi- infinity body due to short time of cooling and final speed of heat distribution. According to Table II, cooling time within interval of temperatures $875^{\circ} \mathrm{C}$ $-150{ }^{\circ} \mathrm{C}$ in average is equal to $0.68 \mathrm{~s}$, where film and nucleate boiling processes cannot be developed. Accurate experiments of French showed that film boiling process during quenching in electrolytes was completely absent. However, among the leading experts it was widely distributed opinion that during quenching in liquid media three classical stages of cooling take place: developed film boiling, nucleate boiling and convection. It is based on well-known heat conductivity law of Fourier (2) which is written as [15]:

$$
q=-\lambda \frac{\partial T}{\partial r}
$$

Here $\mathrm{q}$ is heat flux density in $\mathrm{MW} / \mathrm{m}^{2} ; \lambda$ is thermal conductivity in $\mathrm{W} / \mathrm{mK}$.

According to Eq. (2), during immersion of heated to high temperatures steel parts into cold liquid, at the very beginning of cooling initial heat flux density tends to infinity. It means that, according to Eq. (2), initial heat flux density always accedes the first critical heat flux density $\mathrm{q}^{\text {crl }}$ providing developed film boiling process. That is why three types of heat transfer modes were accepted as a classical knowledge. However, accurate experiments of French showed absence of film boiling process during quenching from $875^{\circ} \mathrm{C}$ of different steel probes in cold electrolyte (see Table II). Accurate experiments of French are supported by modified law of Fourier (see Eq. (3)) [15]:

$$
q=-\lambda \frac{\partial T}{\partial r}-\tau_{r} \frac{\partial T}{\partial \tau}
$$

where $\tau_{r}$ is relaxation time in seconds.

According to modified law of Fourier, initial heat flux density during quenching is always final value which in many cases can be below the first critical heat flux density that guarantees absence of film boiling 
process during quenching in liquid media [16], [17]. Modified law of Fourier generates heat conductivity equation (4) which is successfully used for temperature field calculation during initial process of quenching where temperature gradient is very huge [15].

$$
\frac{\partial T}{\partial \tau}+\tau_{r} \frac{\partial^{2} T}{\partial \tau^{2}}=\operatorname{adiv}(\operatorname{grad} T)
$$

More information on solving hyperbolic heat conductivity equations with non-linear boundary conditions during quenching one can find in published literature [18]-[20].

The most powerful effect on any film boiling elimination makes insulating polymeric layer formation when quenching steel parts in water polymer solutions of inverse solubility [21]-[23]. Polymeric surface layer decreases initial heat flux density below its critical value that prevents film boiling process during steel quenching (see Fig. 3, Fig. 4, and Eq. (5)).

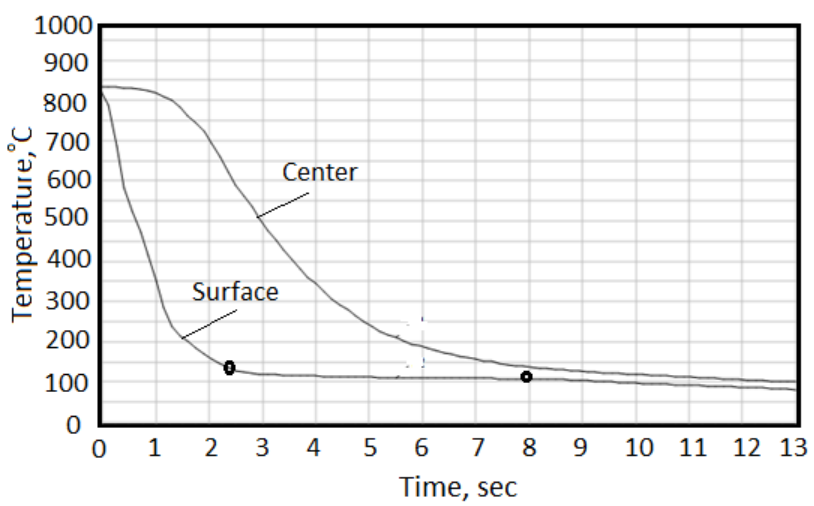

Fig. 3. Surface and core cooling curves versus time during quenching of standard probe in still $1 \%$ water PAG solution at $17{ }^{\circ} \mathrm{C}$.

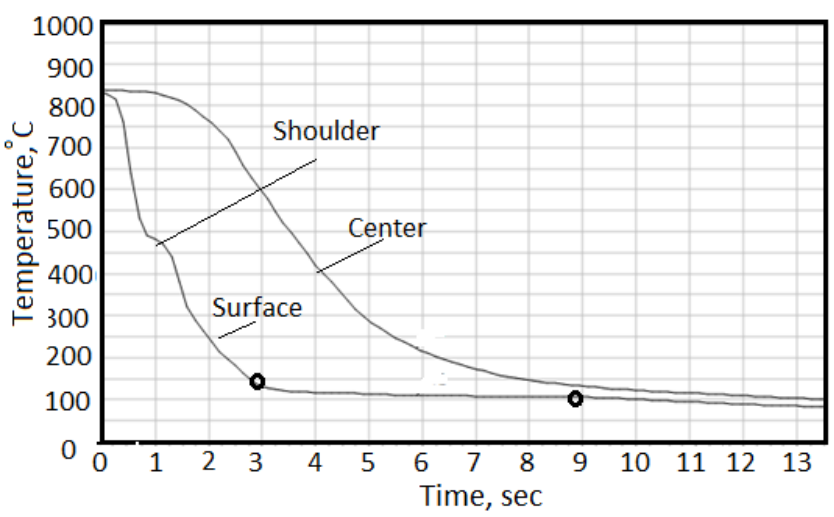

Fig. 4. Surface and core cooling curves versus time during quenching of standard probe instill $1 \%$ water PAG solution at $17{ }^{\circ} \mathrm{C}$ (second experiment)

$$
q_{\text {in }}=\frac{q_{o}}{\left(1+2 \frac{\delta}{R} \frac{\lambda}{\lambda_{\text {coat }}}\right)}
$$

Here $q_{\text {in }}$ is reduced initial heat flux density due to formation a thin insulating layer on the surface of quenched steel part; $q_{o}$ is initial heat flux density to be reduced by insulating layer; $\delta$ is thickness of thin insulating layer; $\mathrm{R}$ id radius of probe; $\lambda$ is thermal conductivity of steel; $\lambda$ coat is thermal conductivity of insulating layer (coating).

As seen from Fig. 3 and Fig. 4, film boiling process during quenching standard probe in $1 \%$ water PAG solution is completely absent. Cooling time in water polymer solution lasts a little bit longer due to thin insulating surface layer formed during quenching. It was also noticed that old PAG polymer loses its inverse solubility effect and with passing time decreases its critical heat flux density. Shoulder formation on the surface cooling curve was observed very rarely (see Fig. 3 and Fig. 4) while film boiling mode was present mostly during quenching in water PAG solutions of elevated concentration (see Fig. 5). 


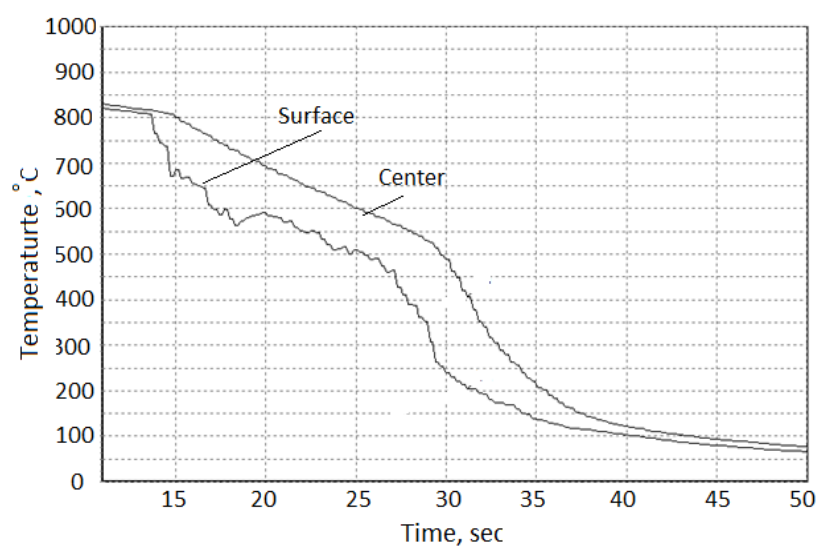

Fig. 5. Surface and core cooling curves versus time during quenching of standard probe in still $20 \%$ water PAG solution at $20{ }^{\circ} \mathrm{C}$.

Duration of film boiling process can be calculated using Eq. (6) [7].

$$
\tau=\left[\frac{k B i_{V}}{2.095+3.867 B i_{V}}+\ln \frac{T_{0}-T_{m}}{T-T_{m}}\right] \frac{K}{a K n}
$$

Here

$$
\begin{aligned}
& B i_{V}=\frac{\alpha}{\lambda} K \frac{S}{V} \\
& K n=\frac{B i_{V}}{\left(B i_{V}^{2}+1.437 B i_{V}+1\right)^{0.5}}
\end{aligned}
$$

Here $B i_{V}$ is generalized Biot number; $T_{o}$ is initial temperature; $T_{s}$ is saturation temperature; $T_{m}$ is bath temperature; $K$ is Kondrat'ev form factor; a is thermal diffusivity of steel; $K n$ is dimensionless Kondrat'ev number; $\alpha$ is heat transfer coefficient; $S$ is Surface; $V$ is volume.

Actually, film boiling process is not required during quenching. Only transient nucleate boiling process is preferable because it is the most uniform and accelerated cooling in liquid media. Accelerated cooling should be interrupted. Cooling time interruption is required to aim:

- Elimination crack formation during accelerated cooling of hardened steel parts.

- Decrease distortion of steel parts after quenching, especially in water polymer solutions.

- Provide viscose core of quenched steel parts that increases surface residual stresses and increases service life.

- $\quad$ Performing IQ - 2 technologies.

\section{SONAR System FOR CONTROLling THE QUALITY OF HARDENED STEEL PARTS}

The method and apparatus for controlling the quality of hardening metals and irons is described in detail in Ukrainian patent No. 119230 [24]. The system analyzes noise produced by transient nucleate boiling process. An apparatus for control quality of quenching is shown in Fig. 6.

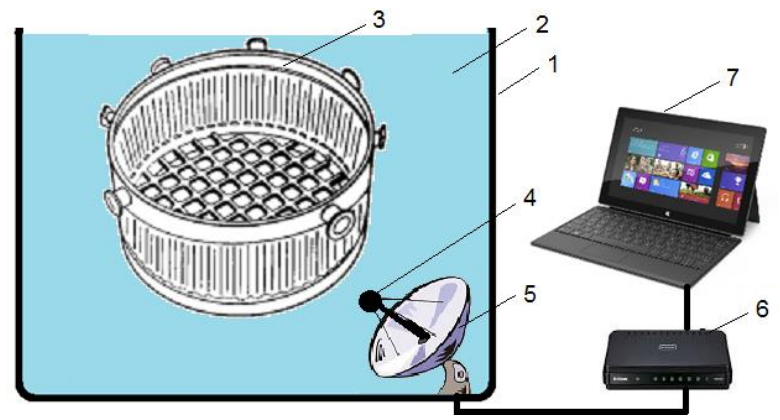

Fig. 6. Apparatus for control quality of hardening in liquid media: 1 is tank; 2 is quenchant; 3 is load where steel ports should be distributed smoothly; 4 is hydrophone; 5 is device for noise focusing; 6 is device that filters industrial noise and transfers data to computer, 7 is computer [24]. 
It is assumed that quality of quenching is measured by a ratio (7) which varies from 1 to 3 and more depending on duration of film boiling process.

$$
Q=\tau_{\text {exp }} / \tau_{n b}
$$

Here $\tau_{\exp }$ is duration of boiling process that includes film and nucleate boiling modes which is measured by sonar system shown in Fig. 6; $\tau_{n b}$ is duration of transient nucleate boiling when film boiling is completely absent which is calculated by Eq. (1). In this case cooling is uniform and the ratio (7) is equal to 1 . When the ratio (7) is between 1 and 1.3, some local vapor films appear during quenching. When the ratio (7) is equal to 3, developed film boiling process is observed during quenching (see Fig. 5 and Table III).

TABLE III: AdVANTAgES AND Disadvantages OF QUENCHING PROCESS DEPENDING ON A RATIO $\tau_{\exp } / \tau_{n b}$

\begin{tabular}{|c|c|c|}
\hline$\tau_{\text {exp }} / \tau_{n b}$ & Type of boiling process & $\begin{array}{l}\text { Advantages and disadvantages of } \\
\text { quenching }\end{array}$ \\
\hline 1 & Any film boiling is absent & $\begin{array}{l}\text { Minimal distortion, uniform and high } \\
\text { surface hardness }\end{array}$ \\
\hline $1-1.3$ & Local film boiling prevails & $\begin{array}{l}\text { High distortion, possibility of quench } \\
\text { process formation. }\end{array}$ \\
\hline $1.3-3$ and more & Developed film boiling & $\begin{array}{l}\text { Non- uniform and low surface } \\
\text { hardness of quenched components }\end{array}$ \\
\hline
\end{tabular}

Along with the local film boiling effect that increases distortion of quenched steel parts, strong quenchant agitation also can increase distortion of quenched steel parts in water solutions of inverse solubility polymers caused by local dissolving of surface polymeric layer (see Fig. 7). Accelerated martensite transformation in the dissolved area results in increased distortion due to its specific volume changing. Moderate agitation of water polymer solution and cooling time interruption can essentially decrease distortion after quenching. Moderate agitation can be performed by hydrodynamic emitters which destroy film boiling processes creating resonance effect during quenching in liquid media [22], [25].

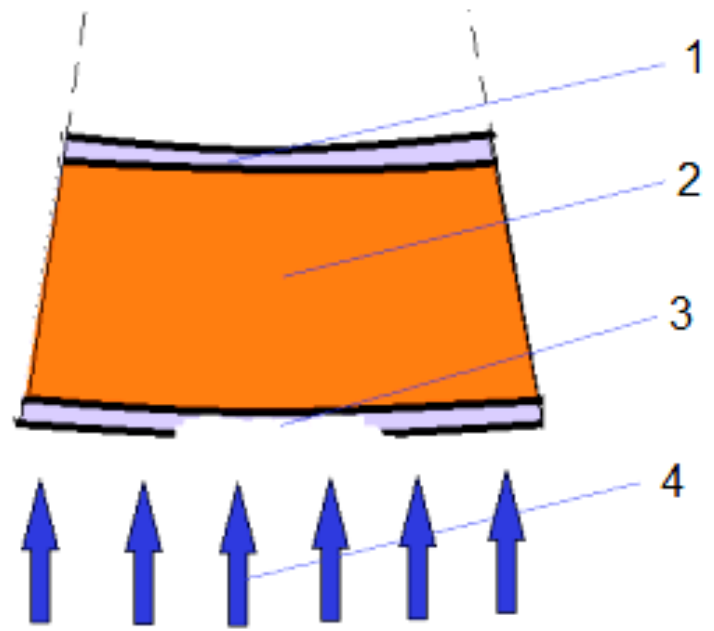

Fig. 7. A scheme explaining why a big distortion takes place during quenching in water PAG polymer solutions caused by dissolving polymeric surface layer [22]: 1 - polymer coating; 2 - quenched steel part; 3 - locally dissolved by water flow polymer coating that provides non-uniform cooling; 4 - water flow.

From the literature is known that heat transfer coefficient (HTC) during film boiling process is equal to $500 \mathrm{~W} / \mathrm{m}^{2} \mathrm{~K}$. Using experimental data presented in Fig. 5 and solving inverse problem, one can come to conclusion that average HTC during film boiling is $520 \mathrm{~W} / \mathrm{m}^{2} \mathrm{~K}$. For this condition generalized Biot number $\mathrm{Bi}_{\mathrm{V}}$ is equal to 0.049 and Kondrat'ev number $\mathrm{Kn}$ is equal to 0.046 . Kondrat'ev coefficient $\mathrm{K}$ for standard cylindrical probe 12.5 diameter is equal to $6.75 \times 10^{-6} \mathrm{~m}^{2}$. When cooling from $800{ }^{\circ} \mathrm{C}$, average thermal diffusivity of material is equal to $5.3 \times 10^{-6} \mathrm{~m}^{2} / \mathrm{s}$. Taking these initial and thermal properties data into account, cooling time from $800{ }^{\circ} \mathrm{C}$ to $600{ }^{\circ} \mathrm{C}$ and $525^{\circ} \mathrm{C}$ during film boiling was calculated using equation (6) to compare it with the experiment that is provided in Table IV. 
TABLE IV: CoOling Time of StANDARd Probe From $800^{\circ} \mathrm{C}$ TO DifFERENT Probe Core TEMPERATURES DURING FILM BOILING PROCESS

\begin{tabular}{ccc}
\hline Core temperature. ${ }^{\circ} \mathrm{C}$ & $\begin{array}{c}\text { Cooling time } \\
\text { Experiment }\end{array}$ & $\begin{array}{c}\text { in seconds } \\
\text { Calculated by Eq. (1) }\end{array}$ \\
\hline 525 & 14.9 & 14.98 \\
600 & 10 & 10.5 \\
\hline
\end{tabular}

It should be noted here that, according to experimental data published by ASTM Standard D 6482-06, film boiling during quenching in fresh $20 \%$ water PAG solution is absent [1]. In this case, increasing cooling time is explained by increasing the thickness of the surface insulating layer that decreases heat flux density during quenching. However, the developed film boiling process was clearly observed only in very old water PAG solution which doesn't show a tendency of shoulder formation on a surface cooling curve (see Fig. 5).

Similar calculations can be fulfilled for transient nucleate boiling process (see Fig. 4 and Fig. 5). According to the investigations of the author [22], the effective Kondrat'ev number Kn is equal to 0.3.

TABle V: CoOling Time of Standard Probe From $800{ }^{\circ} \mathrm{C}$ To DifFerent Probe Core Temperatures WheN

\begin{tabular}{|c|c|c|}
\hline \multicolumn{3}{|c|}{ FILM BOILING PROCESS IS ABSENT } \\
\hline Core temperature. ${ }^{\circ} \mathrm{C}$ & $\begin{array}{l}\text { Cooling time } \\
\text { Experiment }\end{array}$ & $\begin{array}{c}\text { in seconds } \\
\text { Calculated by Eq. (1) }\end{array}$ \\
\hline 250 & 4.1 & 4.4 \\
\hline 150 & 7.5 & 7.05 \\
\hline
\end{tabular}

Total cooling time, in this case, is calculated as:

$$
\tau=\tau_{F B}+\tau_{n b}
$$

Here FB means film boiling process and $\mathrm{nb}$ means transient nucleate boiling process.

Cooling in fresh PAG solutions and very old (aged) polymer solutions differ significantly from each other (see Table VI). This phenomenon is explained by decreasing critical heat flux density with the aging of water polymer solution.

TABLE VI: COOLING TIME FROM $850{ }^{\circ} \mathrm{C}$ TO $250{ }^{\circ} \mathrm{C}$ DURING QUENCHING IN WATER PAG SOLUTIONS AT ROOM TEMPERATURE AND AGITATION $0.5 \mathrm{M} / \mathrm{s}$

\begin{tabular}{ccc}
\hline $\begin{array}{c}\text { Concentration } \\
\%\end{array}$ & Cooling time & in seconds \\
Fresh solution & Old solution \\
\hline 5 & 4.3 & - \\
10 & 4.75 & - \\
15 & 6.25 & - \\
20 & 10 & 32 \\
\hline
\end{tabular}

As one can see from Table VI, the difference in cooling duration is very large.

\section{DISCUSSION}

As a rule, alloy and high alloy steels are quenched in oils or high concentration of water polymer solutions to decrease distortion and prevent crack formation during quenching. The agitation of coolant lasts all time and is not interrupted and it is mainly used to eliminate the film boiling process. However, during batch quenching, liquid stream faces essential hydrodynamic resistance and its penetration is not enough strong to provide uniform cooling inside the batch load. This paper shows that a low concentration of PAG water polymer solutions always provides uniform cooling due to stable surface polymeric layer formation that decreases initial heat flux density below its critical value. Quench process in low concentration of inverse solubility polymers is intensive within transient nucleate boiling and slow cooling during convection. To prevent quench crack formation, accelerated cooling should be interrupted at proper time. Also, interruption is required to prevent dissolving a thin polymeric layer at the bottom of the batch load. Since quenching in low concentration of water polymer solutions is intensive, in many cases instead of alloy and high alloy steels the optimal hardenability steels can be successfully used [25]. Optimal hardenability steel provides high surface compressive residual stresses resulting in super strengthened material in surface layers. All of these increases service life of hardened components. Based on current achievements, it makes sense to start mass implementation of low concentration inverse solubility polymers as a quenchant and replacement of alloy and high alloy steels by optimal hardenability steels to save alloy elements, increase the service life of hardened materials and improve environmental conditions. The next step of improving the proposed technology consists in exploring hydrodynamic emitters that helps destroy effectively film boiling processes. 


\section{CONCLUSIONS}

1. When quenching in a low concentration of inverse solubility water polymer solutions, film boiling is absent due to the formation of a thin surface polymeric layer. In this case, the transient nucleate boiling process duration is directly proportional to the squared thickness of quenched component and inversely proportional to thermal diffusivity of its material, depending on the shape of component and cooling characteristics of a cooling system if initial temperatures are fixed.

2. Quality quenching control during hardening in water polymer solutions can be performed via measurement of transient film and nucleate boiling processes duration which should be compared with the pure nucleate boiling.

3. Cooling time interruption during quenching in water polymer solutions provides several benefits such as decreased distortion, crack formation elimination, surface compressive residual stresses formation that increases the service life of hardened components.

4. Optimizing the quench process in liquid media is possible if the physics of transient film and nucleate boiling processes are deeply enough investigated and introduced by appropriate mathematical equations.

\section{REFERENCES}

[1] ASTM Standard Test Method for Determination of Cooling Characteristics of Aqueous Polymer Quenchants by Cooling Curve Analysis with Agitation, D 6482-06.

[2] Heat Treatment of Steel Handbook, Marcel Dekker, NY, 1997, pp. 157-149.

[3] Totten G.E., Bates C.E., and Clinton N.A. Handbook of Quenchants and Quenching Technology, Materials Park, ASM International, 1993, ch. 5, pp. 161-190.

[4] Beck J.V., Blackwell B., and Clair C.R.St. Inverse Heat Conduction: Ill-Posed Problems, New York, Wiley - Interscience, 1985.

[5] Kobasko N. Uniform and Intense Cooling During Hardening Steel in Low Concentration of Water Polymer Solutions. American Journal of Modern Physics. 2019; 8(6): 76-85.

[6] Kobasko N.I., Uniform and Intense Cooling During Hardening Steel in Low Concentration of Water Polymer Solutions Ibtissem, BELGACEM, Prime Archives in Physics. Hyderabad, India: Vide Leaf, 2020.

[7] Kobasko N.I., Aronov M.A., Powell J.A., G.E. Totten, Intensive Quenching Systems: Engineering and Design. ASTM International, USA, 2010, 234. doi: 10.1520/mnl64-eb.

[8] French H.J. The Quenching of Steels. Cleveland, Ohio, USA: American Society for Steel Treating, 1930.

[9] Kobasko N. High Quality Steel vs Surface Polymeric Layer Formed during Quenching, Germany, Lambert Academic Publishing, 2019, ch. 4, pp. 29-57.

[10] Kobasko N. Austempering Processes that are Performed via Cold Liquids, Germany, Lambert Academic Publishing, 2019, ch. 9-11, pp. 61-84.

[11] Kobasko N.I., Moskalenko A.A. Mechanism of Transient Nucleate Boiling Process Development during Hardening Metals and Irons in Electrolytes, Global Journal of Scientific and Research Publications (GJSRP), 2021; 1(5): 14-20.

[12] Kobasko N. I. Self-regulated thermal processes during quenching of steels in liquid media. International Journal of Microstructure and Materials Properties, 2005; 1 (1), 110-125. doi: 10.1504/ijmmp.2005.008135.

[13] Kobasko N. Investigation of transient nucleate boiling processes and their practical use in heat treating industry, EUREKA: Physics and Engineering, 2017; 5:39-48. DOI: 10.21303/2461-4262.2017.00409.

[14] Kobasko, N. I. Self - regulated thermal process, its main characteristics and practical application. International Journal of Current Research, 2016; 8 (11):41698-41704.

[15] Lykov A. V. Teoriya Teploprovodnosti [Theory of Heat Conductivity]. Moscow: Vysshaya Shkola, $596,1967$.

[16] Tolubinsky V.I. Heat Transfer at Boiling. Kyiv: Naukova Dumka, 1980.

[17] Kutateladze S. S. Fundamentals of Heat Transfer, Academic Press, New York, 1963.

[18] Guseynov Sh. E., Rimshans J.S., and Kobasko N.I. On one non - linear mathematical model for intensive steel quenching and its analytical solution in closed form, Progress in Industrial Mathematics at ECMI (Mathematics in Industry 15), A.D. Fitt et. al. Eds., Springer- Verlag, Berlin, Heidelberg, 2010, pp. 857-862.

[19] Kobasko N., Guseynov Sh., and Rimshans J. Core Hardness and Microstructure Prediction in Any Steel Part, Germany, Lambert Academic Publishing, 2019, ch. 12, pp. $72-76$.

[20] Buikis A. Multidimensional Mathematical Models for Intensive Steel Quenching, Germany, Lambert Academic Publishing, 2020 , ch. 3, pp. 66-88.

[21] Kobasko N. I. Real and Effective Heat Transfer Coefficients (HTCs) Used for Computer Simulation of Transient Nucleate Boiling Processes during Quenching. Materials Performance and Characterization, 2012; 1 (1), MPC - 2012-0012. doi: 10.1520/mpc-2012-0012.

[22] Kobasko N. Advanced Quenching Technologies, Germany, Lambert Academic Publishing, 2021, 122 p.

[23] Kobasko N. I. Designing of advanced and original austempering processes based on thermal science and engineering physics approaches. EUREKA: Physics and Engineering, 2016; 2, 43-50.

[24] Kobasko N.I., Moskalenko A.A., and Dobryvechir V.V. Method and Apparatus for Quality Control of Metal Components in Liquid Media, UA Patent No. 119230.

[25] Kobasko N. Optimal Hardenability Steel and Method for Its Composing, Germany, Lambert Academic Publishing, 2018, ch. 58, pp. 29-58. 